\title{
The evolution of health status and chronic conditions in Catalonia, 1994-2006: the paradox of health revisited using the Blinder - Oaxaca decomposition
}

\author{
Anna García-Altés ${ }^{1,2,3,6^{*}}$, Jaime Pinilla ${ }^{4}$ and Vicente Ortún ${ }^{5,6}$
}

\begin{abstract}
Background: The paradox of health refers to the improvement in objective measures of health and the increase in the reported prevalence of chronic conditions. The objective of this paper is to test the paradox of health in Catalonia from 1994 to 2006.

Methods: Longitudinal cross-sectional study using the Catalonia Health Interview Survey of 1994 and 2006. The approach used was the three-fold Blinder - Oaxaca decomposition, separating the part of the differential in mean visual analogue scale value (VAS) due to group differences in the predictors (prevalence effect), due to differences in the coefficients (severity effect), and an interaction term. Variables included were the VAS value, education level, labour status, marital status, all common chronic conditions over the two cross-sections, and a variable for noncommon chronic conditions and other conditions. Sample weights have been applied.

Results: Results show that there is an increase in mean VAS for men aged 15-44, and a decrease in mean VAS for women aged 65-74 and 75 and more. The increase in mean VAS for men aged 15-44 could be explained by a decrease in the severity effect, which offsets the increase in the prevalence effect. The decrease in mean VAS for women aged 65-74 and 75 and more could be explained by an increase in the prevalence effect, which does not offset the decrease in the severity effect.

Conclusions: The results of the present analysis corroborate the paradox of health hypothesis for the population of Catalonia, and highlight the need to be careful when measuring population health over time, as well as their usefulness to detect population's perceptions.
\end{abstract}

Keywords: health status chronic conditions, prevalence, severity, Blinder - Oaxaca decomposition

\section{Background}

The assessment of the health status of populations has important consequences in health policy. Arguments in favour of limiting health spending due to its low marginal productivity have no value if health spending is not assessed in parallel with changes in population health status as a consequence of this spending. Along with the assessment of benefits in terms of changes in health status it is also relevant to analyze allocation of resources among health programs, as is the case of a

\footnotetext{
* Correspondence: annagarcia@post.harvard.edu

${ }^{1}$ Agència de Salut Pública de Barcelona, Spain

Full list of author information is available at the end of the article
}

standard economic evaluation. Finally, health status has also influence in other individual behaviours, such as labour market decisions, and investment in health [1-4].

Data shows that objective measures of health have been continuously improving in developed countries. Catalonia is one of the 17 Autonomous Communities of Spain situated in the northeast of Spain, with an area of $31,895 \mathrm{~km}^{2}$. Catalonia, as the rest of Spain, has a National Health Service financed mainly by taxes, which provides universal and free healthcare coverage. Over the period 1994-2006, population grew from 6.09 million inhabitants to 7.13 million; the percentage of foreign population increased (1.61\% to $12.81 \%)$, as well as the

\section{C) Biomed Central}


percentage of population over 65 years old $(15.70 \%$ to 16.39\%). Life expectancy increased for men from 74.8 years in 1994 to 78.2 years in 2006; for women, life expectancy was 82.0 years in 1994 and went up to 84.5 years in 2006 [5]. However, there has also been an increase in the reported prevalence of chronic conditions, and doctor consultations. This fact (improvement in objective measures of health and increase in the reported prevalence of chronic conditions) has been coined as "the paradox of health", and several factors have been suggested to explain it: the decrease in mortality due to acute diseases, increase in the awareness of bodily symptoms, changes over time on diagnosing illness, commercialization of health, and increase in the expectation of being cured [6-8].

The consequences of the increase in the reporting of chronic conditions are many. In particular, chronic conditions have a direct impact when measuring the health status of populations using EQ-5D: it leads to more severe health states, worse health status and decreases in health capital estimation. In Catalonia were this instrument has been used, it has been reported that the health of the Catalan population has worsened from 1994 to 2006, especially for women, contradicting the observed improvements in life expectancy [9]. Also for Sweden, results for 1980/81 and 1996/97 showed considerable health gains for older people and small or non-existent gains for younger women [10].

The objective of this paper is to test "the paradox of health" in Catalonia, analysing health status changes from 1994 to 2006, and decomposing the estimated differences into three components: a "prevalence effect" of chronic conditions, a "severity effect", and an interaction due to simultaneous differences in prevalence and severity of chronic conditions between these years.

\section{Methods}

A longitudinal cross-sectional study was carried out using the Catalonia Health Survey of 1994 and 2006 (i.e. not panel data). The Catalonia Health Survey collects, by means of direct personal interviews, demographic variables, self-assessed health status, chronic diseases, perceived morbidity, utilization of healthcare services and drugs, health-related lifestyles, and healthcare coverage. The study population corresponded to the survey sample of the interviews, i.e. adults in Catalonia excluding those institutionalized, and the unit of analysis corresponding to the individuals that responded to the surveys of $1994(\mathrm{n}=15,000)$, and $2006(\mathrm{n}=15,553)$.

To test "the paradox of health", we decomposed the change in health status from 1994 to 2006 for every sex and age group (15-44, 45-64, 65-74, and 75 years old and more) into three components: a "prevalence effect" due to year differences in the distribution of chronic conditions, a "severity effect" due to year differences in the impact of these conditions on population health, and an interaction due to simultaneous differences in prevalence and severity between the two years. Health status was measured using the visual analogue scale (VAS) of the EQ-5D instrument that the survey includes to measure quality of life and utilities [11]. We controlled for socio-demographic variables that may be related with health status (i.e. education level, labour status, marital status). The variables included in the model and their categorizations are:

- Health status: VAS value, measured from 0 ("worst imaginable health state") to 100 ("best imaginable health state").

- Education level, coded 1 to 4: non studies, primary studies, secondary studies, university studies.

- Labour status, coded 1 to 5: employed, unemployed, home work, retired, student.

- Marital status, coded 1 to 4: single, married, divorced, widowed.

- All common chronic conditions over the two cross-sections. Respondents are asked: "Do you currently have or did your doctor tell you that you had any of the following chronic conditions?" The common conditions were hypertension, varicose veins, osteoarthritis, allergy, bronchitis, diabetes, duodenal ulcer, high cholesterol, cataracts, constipation, nervous problems-depression, embolism, cardiac problems, asthma, skin problems (for each: "no $=0$ ", "yes $=1$ "). Prostate or urinary problems, despite being common, were not included because of collinearity problems.

- A variable for non-common chronic conditions and other conditions. Non-common conditions over the two cross-sections were migraine, back pain, blood circulation problems, moraines, thyroid problems, cancer tumor, anemia, heart attack, cervical pain, osteoporosis, incontinence problems. The construction of the variable also included "other conditions", filled in both surveys as free text. The composite variable was coded "no $=0$ ", "yes $=1$ ".

For every sex and age group, a linear regression was run to relate VAS values with all demographic and chronic condition variables. We used "non studies", "employed", and "married", as reference categories of the categorical variables. Variables with statistically significant coefficients were included in the decomposition. The decomposition approach we adopted is the well-known one from labour economics associated with Blinder - Oaxaca [12,13], that has become a standard technique for decomposing gaps in outcomes such as wages between different population groups (according 
to sex, race, or any other characteristic), although we used the three-fold decomposition variant.

Given two groups (1994 and 2006), an outcome variable (mean VAS), and a set of predictors, the question is how much of the mean outcome difference $\mathrm{R}$, where:

$$
\mathrm{R}=\mathrm{E}\left(\operatorname{vas}_{2006}\right)-\mathrm{E}\left(\operatorname{vas}_{1994}\right)
$$

is accounted for by group differences in the predictors. Based on the linear model:

$$
\mathrm{Y}_{\mathrm{i}}=\mathrm{X}_{\mathrm{i}}^{\prime} \beta_{\mathrm{i}}+\varepsilon_{\mathrm{i}}
$$

where $Y_{i}$ refers to the outcome (mean VAS) for each group (1994 and 2006), $X_{i}^{\prime}$ is a vector of characteristics (sociodemographic and chronic conditions), $\beta_{\mathrm{i}}$ is the associated parameter vector, and $\varepsilon_{\mathrm{i}}$ is an error term. The three-fold Blinder - Oaxaca decomposition breaks down the difference between 2006 and 1994 in the following way [14]:

$$
\begin{aligned}
& \mathrm{R}=\left[\mathrm{E}\left(\mathrm{X}_{2006}\right)-\mathrm{E}\left(\mathrm{X}_{1994}\right)\right]^{\prime} \beta_{1994}+\mathrm{E}\left(\mathrm{X}_{1994}\right)^{\prime}\left(\beta_{2006}-\beta_{1994}\right)+ \\
& +\left[\mathrm{E}\left(\mathrm{X}_{2006}\right)-\mathrm{E}\left(\mathrm{X}_{1994}\right)\right]^{\prime}\left(\beta_{2006}-\beta_{1994}\right)
\end{aligned}
$$

where $E\left(v^{2} s_{2006}\right)$ is the predicted mean VAS for 2006 , $\mathrm{X}_{2006}$ is the mean vector of characteristics for 2006 that determine VAS, and $\beta_{2006}$ is the vector of estimated returns to VAS determinants for 2006 (likewise for 1994). The first summand of the right hand side accounts for the part of the differential that is due to group differences in the predictors ("prevalence effect"), the second measures the contribution of differences in the coefficients ("severity effect"), while the third summand is an interaction term accounting for the fact that differences in endowments and coefficients exist simultaneously between the two groups.

Blinder - Oaxaca decompositions have typically been carried out using linear regression models owing the attractive property that such models fit exactly at the mean of the sample, but the approach has also been used for binary, ordered and count models $[15,16]$. The analysis above assumes that the dependent variable is continuous. In this paper, the dependent variable is an ordered categorical variable, albeit with quite a high number of categories (from 0 to 100). While Blinder Oaxaca type decompositions can be carried out with ordered response models, non-linear approximations make impossible to estimate the contribution of each individual variable to the prevalence and severity effects.

Although VAS data was not normally distributed, we choose to model untransformed data. Transformations, such as log or square root are often proposed, but provide estimates with difference on a scale not relevant to policy making interpretation [17]. Moreover, the assumption of normality is primarily a convenience for the purpose of statistical inference; when this assumption fails to hold, the estimates of fixed and random parameters will still be consistent, though the standard error estimates will be inconsistent in small samples [18].

So, we estimated and carried out the decomposition assuming that VAS is a continuous variable and employed the linear specification above. To check for the consistency of this procedure we compared the results obtained using the linear Blinder - Oaxaca decomposition and the non-linear one (ordered probit specification). Since the number of values was different from 1994 to 2006 (i.e., the scale has the same 0 to 100 values, but people responded to a different number of categories in both years), we recoded VAS values into 20 groups (grouping VAS values in groups of 5), and run both the ordered probit specification and the linear one.

Sample weights have been applied. Significance level was set at $\mathrm{p}=0.05$. All analyses were performed using Stata 10.1, using the oaxaca command.

\section{Results}

Table 1 shows the frequencies of the variables included in the model for every sex and age group. The sex distribution is similar in the two surveys and the age distribution changes slightly, showing an increase from 1994 to 2006 in the 15-44 group, and in the 75 years and older age -especially for women- owing to the changes in the demography of Catalonia. There is also an increase of men and women undertaking secondary and university studies, and an increase in the proportion of people employed between these years.

Table 2 shows the prevalence of chronic conditions by sex and age group. Both men and women tend to declare more chronic conditions through time, especially nervous problems-depression, high cholesterol, and cataracts. A few conditions have decreased in prevalence, such as osteoarthritis in both sexes and bronchitis among men. Table 3 shows mean VAS values by sex and age group. VAS has statistically significantly increased for men aged 15-44 years (from 77.57 in 1994 to 79.02 in 2006) and has decreased for women aged 65-74 years (58.92 to 55.13) and 75 and more years old (56.32 to 50.43); Figure 1 shows graphically the change over time in the distribution of VAS by sex and age group.

Regarding the results of the Blinder - Oaxaca decomposition, Table 4 shows the contribution of each variable to the prevalence effect, the severity effect and their interaction to the gap in VAS. For men aged 15-44 years, if the prevalence of chronic conditions in 1994 would be that of 2006, mean VAS would be lower (-0.396), corresponding to the increase in prevalence of 2006. On the other side, if the severity of chronic conditions in 1994 would be that of 2006, mean VAS would be higher (1.714). So, the increase of 1.504 in mean VAS is mainly 
Table 1 Socio-demographic characteristics by sex and age group

\begin{tabular}{|c|c|c|c|c|c|c|c|c|}
\hline & \multicolumn{2}{|c|}{ Men 15-44 } & \multicolumn{2}{|c|}{ Men 45-64 } & \multicolumn{2}{|c|}{ Men $65-74$} & \multicolumn{2}{|c|}{ Men 75 \& more } \\
\hline & 1994 & 2006 & 1994 & 2006 & 1994 & 2006 & 1994 & 2006 \\
\hline $\bar{N}$ & 3,030 & 4,097 & 1,747 & 2,240 & 715 & 801 & 380 & 743 \\
\hline Age group & 52.83 & 56.24 & 29.73 & 27.69 & 11.42 & 8.86 & 6.02 & 7.21 \\
\hline Married & 41.15 & 39.22 & 88.76 & 82.61 & 88.28 & 86.18 & 71.14 & 76.94 \\
\hline Single & 58.06 & 58.34 & 7.11 & 9.28 & 4.19 & 6.32 & 3.33 & 5.45 \\
\hline Divorced & 0.76 & 2.38 & 2.03 & 6.09 & 1.30 & 1.93 & 0.82 & 0.65 \\
\hline Widow & 0.03 & 0.06 & 2.10 & 2.02 & 6.23 & 5.57 & 24.71 & 16.96 \\
\hline Employed & 61.84 & 80.57 & 67.70 & 77.92 & 2.67 & 3.60 & 0.52 & 0.74 \\
\hline Unemployed & 13.55 & 4.81 & 10.69 & 7.07 & 0.00 & 0.71 & 0.00 & 0.12 \\
\hline Home work & 0.00 & 0.06 & 0.00 & 0.15 & 0.00 & 0.17 & 0.00 & 0.43 \\
\hline Retired & 0.11 & 0.28 & 12.09 & 8.45 & 92.23 & 91.03 & 95.33 & 93.19 \\
\hline Student & 24.5 & 14.28 & 9.52 & 6.41 & 5.10 & 4.49 & 4.15 & 5.52 \\
\hline Non studies & 1.38 & 2.56 & 15.69 & 9.49 & 21.82 & 30.76 & 32.75 & 42.65 \\
\hline Primary studies & 49.41 & 38.35 & 61.76 & 48.83 & 64.59 & 48.05 & 56.39 & 41.08 \\
\hline Secondary studies & 37.64 & 41.15 & 11.40 & 23.96 & 8.12 & 11.98 & 5.51 & 9.87 \\
\hline \multirow[t]{3}{*}{ University studies } & 11.57 & 17.94 & 11.15 & 17.72 & 5.47 & 9.21 & 5.35 & 6.40 \\
\hline & \multicolumn{2}{|c|}{ Women $15-44$} & \multicolumn{2}{|c|}{ Women 45-64 } & \multicolumn{2}{|c|}{ Women $65-74$} & \multicolumn{2}{|c|}{ Women 75 \& more } \\
\hline & 1994 & 2006 & 1994 & 2006 & 1994 & 2006 & 1994 & 2006 \\
\hline $\mathrm{N}$ & 3,229 & 3,797 & 1,935 & 2,226 & 871 & 902 & 660 & 1,120 \\
\hline Age group & 49.29 & 50.52 & 28.76 & 27.70 & 12.65 & 10.01 & 9.30 & 11.77 \\
\hline Married & 50.53 & 47.10 & 82.06 & 75.78 & 61.94 & 65.23 & 20.40 & 30.28 \\
\hline Single & 46.28 & 47.63 & 5.47 & 7.95 & 7.33 & 4.64 & 7.75 & 8.31 \\
\hline Divorced & 2.93 & 4.88 & 3.95 & 9.54 & 1.26 & 3.27 & 1.29 & 0.68 \\
\hline Widow & 0.26 & 0.39 & 8.52 & 6.73 & 29.47 & 26.86 & 70.56 & 60.73 \\
\hline Employed & 43.55 & 69.80 & 27.95 & 52.44 & 0.96 & 2.18 & 0.13 & 0.47 \\
\hline Unemployed & 12.95 & 6.65 & 3.68 & 5.45 & 0.08 & 0.48 & 0.00 & 0.69 \\
\hline Home work & 20.59 & 9.73 & 59.13 & 32.65 & 51.53 & 46.07 & 42.06 & 43.52 \\
\hline Retired & 0.00 & 0.11 & 4.12 & 4.58 & 40.79 & 46.78 & 50.51 & 49.26 \\
\hline Student & 22.91 & 13.71 & 5.12 & 4.88 & 6.64 & 4.49 & 7.30 & 6.06 \\
\hline Non studies & 2.08 & 2.02 & 21.87 & 15.29 & 34.86 & 45.89 & 46.55 & 59.75 \\
\hline Primary studies & 47.18 & 32.80 & 64.95 & 50.89 & 58.75 & 43.59 & 49.82 & 32.77 \\
\hline Secondary studies & 37.05 & 40.14 & 7.88 & 20.29 & 4.72 & 7.24 & 2.42 & 4.35 \\
\hline University studies & 13.69 & 25.04 & 5.30 & 13.53 & 1.67 & 3.28 & 1.21 & 3.13 \\
\hline
\end{tabular}

Catalonia, 1994-2006.

due to a decrease in the severity effect. Looking at the specific variables, there is a positive contribution to the prevalence effect of osteoarthritis (it decreases from 1994 to 2006), and a negative contribution of nervous problems-depression and non common chronic conditions (both increase from 1994 to 2006). The severity effect is driven by the positive contribution of nervous problemsdepression, and the negative contribution of osteoarthritis.

For women aged 65-74 years, if the prevalence of chronic conditions in 1994 would be that of 2006, mean VAS would be lower (-2.990), corresponding to the increase in prevalence of 2006. On the other side, if the severity of chronic conditions in 1994 would be that of
2006, mean VAS would be higher (1.966). So, the decrease in mean VAS (-4.055) is due to an increase in the prevalence effect. Regarding the specific variables, there is a negative contribution to the prevalence effect of nervous problems-depression and non common chronic conditions (both increase from 1994 to 2006), and a negative contribution to the severity effect of non common chronic conditions.

For women aged 75 years and more, if the prevalence of chronic conditions in 1994 would be that of 2006, mean VAS would be lower (-5.612), corresponding to the increase in prevalence of 2006. On the other side, if the severity of chronic conditions in 1994 would be that 
Table 2 Prevalence of chronic conditions by sex and age group

\begin{tabular}{|c|c|c|c|c|c|c|c|c|}
\hline & \multicolumn{2}{|c|}{ Men 15-44 } & \multicolumn{2}{|c|}{ Men 45-64 } & \multicolumn{2}{|c|}{ Men 65-74 } & \multicolumn{2}{|c|}{ Men 75 \& more } \\
\hline & 1994 & 2006 & 1994 & 2006 & 1994 & 2006 & 1994 & 2006 \\
\hline Hypertension & 4.71 & 5.77 & 19.35 & 28.93 & 30.16 & 46.99 & 27.97 & 40.11 \\
\hline Cardiac problems & 1.60 & 2.18 & 7.74 & 7.94 & 16.56 & 20.41 & 21.44 & 29.65 \\
\hline Varicose veins & 2.55 & 3.38 & 8.00 & 13.46 & 10.78 & 15.71 & 13.59 & 21.01 \\
\hline Osteoarthritis & 10.51 & 3.07 & 34.34 & 20.92 & 45.84 & 42.26 & 42.98 & 49.91 \\
\hline Allergy & 13.58 & 16.35 & 8.27 & 13.64 & 6.62 & 11.05 & 8.34 & 11.08 \\
\hline Asthma & 3.89 & 4.84 & 4.29 & 4.37 & 7.81 & 7.86 & 7.31 & 12.14 \\
\hline Bronchitis & 3.91 & 3.21 & 9.58 & 7.36 & 20.20 & 17.37 & 20.42 & 20.52 \\
\hline Diabetes & 0.92 & 0.97 & 6.48 & 7.81 & 13.17 & 16.49 & 8.42 & 17.14 \\
\hline Duodenal ulcer & 3.54 & 2.97 & 10.52 & 9.46 & 13.19 & 13.49 & 9.65 & 14.15 \\
\hline Cholesterol & 4.27 & 6.39 & 16.72 & 25.65 & 14.09 & 26.16 & 7.95 & 21.75 \\
\hline Cataract & 0.33 & 0.52 & 2.91 & 3.58 & 12.07 & 18.50 & 25.88 & 40.36 \\
\hline Skin problems & 4.71 & 4.87 & 4.69 & 7.26 & 4.82 & 8.63 & 6.48 & 14.06 \\
\hline Constipation & 1.44 & 2.06 & 3.59 & 3.84 & 7.17 & 8.76 & 9.01 & 18.08 \\
\hline Nervous problems & 4.61 & 7.42 & 8.22 & 14.62 & 7.65 & 15.89 & 8.78 & 18.66 \\
\hline Embolia & 0.30 & 4.00 & 1.70 & 1.75 & 3.90 & 4.67 & 7.72 & 8.93 \\
\hline \multirow[t]{3}{*}{ Non common } & 22.51 & 41.52 & 35.70 & 61.24 & 43.62 & 73.04 & 60.33 & 77.43 \\
\hline & \multicolumn{2}{|c|}{ Women 15-44 } & \multicolumn{2}{|c|}{ Women 45-64 } & \multicolumn{2}{|c|}{ Women $65-74$} & \multicolumn{2}{|c|}{ Women 75 \& more } \\
\hline & 1994 & 2006 & 1994 & 2006 & 1994 & 2006 & 1994 & 2006 \\
\hline Hypertension & 3.66 & 5.32 & 27.37 & 24.99 & 42.15 & 51.42 & 42.69 & 52.73 \\
\hline Cardiac problems & 1.89 & 2.06 & 6.72 & 6.57 & 15.14 & 19.45 & 21.81 & 26.55 \\
\hline Varicose veins & 8.64 & 17.84 & 63.97 & 40.41 & 61.97 & 45.31 & 74.94 & 42.23 \\
\hline Osteoarthritis & 15.34 & 4.97 & 57.21 & 41.40 & 73.40 & 73.51 & 66.28 & 76.14 \\
\hline Allergy & 17.32 & 17.92 & 17.49 & 17.60 & 16.13 & 19.75 & 10.77 & 14.77 \\
\hline Asthma & 3.41 & 5.86 & 4.57 & 5.84 & 7.16 & 10.12 & 8.39 & 9.25 \\
\hline Bronchitis & 2.82 & 3.75 & 4.98 & 5.17 & 9.84 & 11.16 & 11.93 & 10.00 \\
\hline Diabetes & 0.73 & 1.08 & 6.98 & 6.95 & 12.99 & 17.43 & 11.23 & 17.95 \\
\hline Duodenal ulcer & 1.96 & 2.47 & 6.56 & 6.45 & 7.67 & 9.28 & 6.51 & 10.01 \\
\hline Cholesterol & 3.22 & 4.28 & 16.57 & 23.53 & 2.48 & 30.41 & 14.28 & 30.18 \\
\hline Cataract & 1.00 & 0.37 & 3.71 & 4.97 & 16.60 & 26.65 & 34.84 & 52.66 \\
\hline Skin problems & 5.46 & 7.25 & 5.21 & 9.02 & 8.77 & 8.78 & 8.19 & 11.56 \\
\hline Constipation & 8.50 & 8.36 & 16.24 & 17.42 & 18.13 & 20.65 & 23.85 & 27.34 \\
\hline Nervous problems & 9.23 & 15.16 & 22.25 & 30.74 & 22.02 & 36.76 & 13.96 & 33.65 \\
\hline Embolia & 0.32 & 0.35 & 1.36 & 0.92 & 3.38 & 5.04 & 6.30 & 7.50 \\
\hline Non common & 25.70 & 58.35 & 40.82 & 79.68 & 48.16 & 88.50 & 56.41 & 87.94 \\
\hline
\end{tabular}

Catalonia, 1994-2006.

of 2006, mean VAS would be higher (0.248). So, the decrease in mean VAS (-5.632) is due to an increase in the prevalence effect. Regarding the specific variables, there is a positive contribution of osteoarthritis (it decreases its prevalence from 1994 to 2006) and a negative contribution to the prevalence effect of nervous problems-depression and non common chronic conditions (both increase their prevalence from 1994 to 2006). Figure 2 shows graphically the contribution of each variable to the prevalence and severity effect, and the interaction between both.
Table 5 shows the gap in VAS and the contribution to the gap by differences in prevalence and severity effects, and the interaction among both, using the linear model and the non-linear one, once the VAS variable has been recoded. The qualitative similarity of the obtained results reassures us in the little influence of the linearity assumption on the results of the paper.

\section{Discussion}

Results of the analysis show that there is an increase in mean VAS for men aged 15-44 years, and a decrease in 
Table 3 Mean VAS values by sex and age group

\begin{tabular}{ccccc}
\hline Sex and age group & $\mathbf{1 9 9 4}$ & $\mathbf{2 0 0 6}$ & Difference & p-value \\
\hline Men 15-44 & $\mathbf{7 7 . 5 7}$ & $\mathbf{7 9 . 0 2}$ & 1.45 & 0.000 \\
\hline Men 45-64 & 71.24 & 70.58 & -0.66 & 0.315 \\
\hline Men 65-74 & 63.96 & 65.20 & 1.24 & 0.293 \\
\hline Men 75 \& more & 59.59 & 58.67 & -0.92 & 0.523 \\
\hline Women 15-44 & 75.74 & 76.44 & 0.7 & 0.121 \\
\hline Women 45-64 & 64.74 & 65.46 & 0.72 & 0.307 \\
\hline Women 65-74 & 58.92 & 55.13 & -3.79 & 0.001 \\
\hline Women 75 \& more & 56.32 & 50.43 & -5.89 & 0.000 \\
\hline Catalonia, 1994-2006. & & & &
\end{tabular}

mean VAS for women aged 65-74 years and 75 years and more. The increase in mean VAS for men aged 15-44 years could be explained by a decrease in the severity effect, which offsets the increase in the prevalence effect. In particular, osteoarthritis increases prevalence and decreases severity; and nervous problemsdepression increase its prevalence and severity. The decrease in mean VAS for women aged 65-74 years and 75 years and more could be explained by an increase in the prevalence effect, which does not offset the decrease in the severity effect. The increase in prevalence is especially notorious for osteoarthritis, nervous problemsdepression and non common conditions.

For the three age and sex groups with statistically significant changes in mean VAS, there has been an increase in the prevalence effect and a decrease in the severity effect. Following the paradox of health, despite the increase in the prevalence of chronic conditions, from 1994 to 2006 there has been an improvement in health status for men aged 15-44 years, both measured as self-perceived health (VAS) and as life expectancy. The improvement in their self-perceived health is due to a decrease in the severity effect that offsets the increase in the prevalence effect of chronic conditions. For women aged 65-74 years and 75 years and more, although there is an improvement of their life expectancy, the prevalence of chronic conditions increases, and their self-perceived health decrease due to an increase in the prevalence effect, which offsets the decrease in the severity effect. Differences among younger men and older women may result from the positive and statistically significant effect of labour status on the prevalence and the severity effect for men aged 15-44 years. These results are consistent with previous research on male and female differences on self-assessed health and chronic conditions [8].

As previously mentioned, several factors could help us to explain the increase in the prevalence effect and the decrease in the severity effect of chronic conditions in self-reported health: the decrease in mortality due to acute diseases; the increase in the awareness of bodily symptoms; the varying idealized states of health and the willingness of an individual to acknowledge sickness; the changes over time in diagnosing illness (people are screened more often, and thresholds are lower); the commercialization of health; the increase in the expectation of being cured; the phenomenon of adaptation to illness and even the conscious misreporting of morbidity to achieve other goals (labour participation and government benefits) [6,19-21].

In particular, it is worth mentioning the considerable increase in the prevalence of some chronic conditions over time, like nervous problems-depression, that could be related to the increase in the availability of drugs for their treatment, and cataracts, which could be explained by the increase in their diagnosis and treatment by means of surgery. On the contrary, osteoarthritis has decreased, probably due to the fact that the questionnaire in 2006 included other related conditions, such as backache and osteoporosis. Bronchitis has also decreased among men, consistent with development of the smoking epidemic in the last century. Also, as this is not panel data, the increase in the diagnosis of chronic conditions could be at the expense of adding less severe individuals to the sample in the most recent cohorts.

The analysis performed is an application of the Blinder Oaxaca decomposition to health data. The Blinder Oaxaca decomposition is widely used to identify and quantify the separate contributions of group differences in measurable characteristics, such as education, experience, marital status, etc., to racial and gender gaps in outcomes. Although this methodology has been extensively applied in labour economics to analyzed wage differentials $[13,14,22]$, its application to health is much less frequent [23-26]. Regarding the use of a linear approximation, the qualitative similarity of the obtained results reassures us that the influence of the linearity assumption on the results of the paper is not that significant.

The work is not absent of limitations. The main one would be the use of self-declared information, both regarding health status and chronic conditions, although a good correlation of subjective health indicators and final outcome indicators, and even healthcare expenditure, is known $[27,28]$. Considerable attention has been devoted to the reliability of self-assessed health status and the scope for contamination by measurement error; and there is evidence of reporting bias [29-31]. Different groups (according to age, gender, education, income, language, or personal experience of illness) appear to interpret the questions within their own specific context and therefore use different reference points when responding to the same question, which may invalidate comparisons and measures of health inequality. Whilst the evidence shows mixed results depending on the 


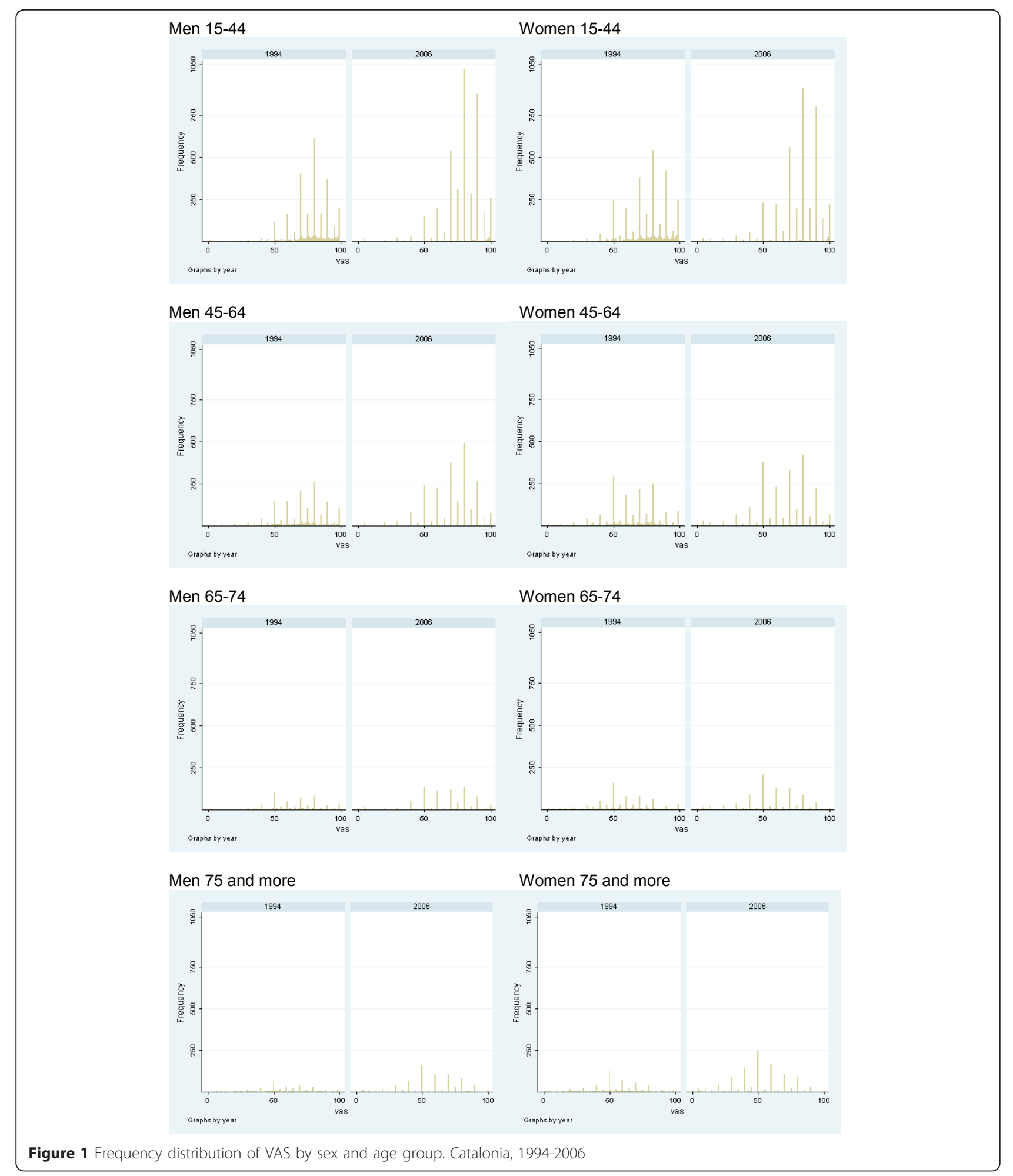

variable analyzed, the methodology used in this study makes it possible to control for age and sex bias in selfreported health, and the year variable reflects the cohort effect. Additionally, one of the advantages of using VAS as the dependent variable is that we do not carry the effect of changes in cut-points that have been previously described in the literature $[30,31]$, or at least they are minimized since we are using a 0 to 100 points scale.

There is some evidence about misreporting of chronic conditions by respondents' level of education and labour 
Table 4 Detailed results of the Blinder-Oaxaca decomposition

\begin{tabular}{|c|c|c|c|c|c|c|c|c|c|}
\hline & \multicolumn{3}{|c|}{ Men $15-44$} & \multicolumn{3}{|c|}{ Women 65 - 74} & \multicolumn{3}{|c|}{ Women $75 \&$ more } \\
\hline & Coef. & Std. Er. & $P>|t|$ & Coef. & Std. Er. & $P>|t|$ & Coef. & Std. Er. & $P>|t|$ \\
\hline Prediction_06 & 79.049 & 0.264 & 0.000 & 54.873 & 0.833 & 0.000 & 50.644 & 0.828 & 0.000 \\
\hline Prediction_94 & 77.545 & 0.299 & 0.000 & 58.928 & 0.742 & 0.000 & 56.277 & 0.828 & 0.000 \\
\hline Difference & 1.504 & 0.399 & 0.000 & -4.055 & 1.115 & 0.000 & -5.632 & 1.170 & 0.000 \\
\hline \multicolumn{10}{|l|}{ Prevalence effect } \\
\hline Studies level & 0.067 & 0.090 & 0.457 & -0.238 & 0.318 & 0.455 & -0.496 & 0.342 & 0.147 \\
\hline Labour status & 0.253 & 0.117 & 0.030 & 0.306 & 0.168 & 0.068 & -0.024 & 0.164 & 0.885 \\
\hline Marital status & - & - & - & - & - & - & -0.382 & 0.239 & 0.110 \\
\hline Hypertension & -0.018 & 0.019 & 0.347 & - & - & - & - & - & - \\
\hline Varicose veins & 0.002 & 0.015 & 0.882 & - & - & - & - & - & - \\
\hline Osteoarthritis & 0.410 & 0.096 & 0.000 & -0.083 & 0.217 & 0.702 & -0.781 & 0.267 & 0.003 \\
\hline Bronchitis & 0.042 & 0.034 & 0.221 & -0.078 & 0.123 & 0.522 & - & - & - \\
\hline Diabetes & -0.001 & 0.004 & 0.768 & -0.199 & 0.135 & 0.139 & -0.336 & 0.186 & 0.071 \\
\hline Duodenal ulcer & 0.035 & 0.032 & 0.262 & -0.099 & 0.099 & 0.319 & - & - & - \\
\hline Cholesterol & -0.035 & 0.036 & 0.321 & - & - & - & - & - & - \\
\hline Constipation & - & - & - & - & - & - & -0.223 & 0.173 & 0.196 \\
\hline Nervous problems & -0.401 & 0.107 & 0.000 & -1.019 & 0.289 & 0.000 & -1.455 & 0.479 & 0.002 \\
\hline Skin problems & -0.004 & 0.015 & 0.787 & - & - & - & - & - & - \\
\hline Embolia & - & - & - & -0.094 & 0.100 & 0.343 & - & - & - \\
\hline Cardiac problems & - & - & - & - & - & - & -0.151 & 0.113 & 0.184 \\
\hline Asthma & - & - & - & - & - & - & -0.065 & 0.098 & 0.504 \\
\hline Non common & -0.745 & 0.144 & 0.000 & -1.489 & 0.548 & 0.007 & -1.698 & 0.476 & 0.000 \\
\hline Total & -0.396 & 0.268 & 0.139 & -2.990 & 0.841 & 0.000 & -5.612 & 0.887 & 0.000 \\
\hline \multicolumn{10}{|l|}{ Severity effect } \\
\hline Studies level & -1.275 & 1.021 & 0.212 & 3.225 & 1.514 & 0.033 & -3.353 & 2.700 & 0.214 \\
\hline Labour status & 7.032 & 2.121 & 0.001 & 6.968 & 1.825 & 0.000 & -8.431 & 3.076 & 0.006 \\
\hline Marital status & - & - & - & - & - & - & -3.044 & 2.549 & 0.233 \\
\hline Hypertension & -0.044 & 0.086 & 0.609 & - & - & - & - & - & - \\
\hline Varicose veins & -0.118 & 0.062 & 0.059 & - & - & - & - & - & - \\
\hline Osteoarthritis & -0.541 & 0.263 & 0.040 & 1.525 & 1.701 & 0.370 & 0.827 & 1.570 & 0.598 \\
\hline Bronchitis & 0.130 & 0.104 & 0.210 & 0.139 & 0.346 & 0.687 & - & - & - \\
\hline Diabetes & -0.036 & 0.032 & 0.269 & -0.035 & 0.377 & 0.926 & 0.324 & 0.346 & 0.350 \\
\hline Duodenal ulcer & 0.098 & 0.089 & 0.273 & 0.288 & 0.265 & 0.277 & - & - & - \\
\hline Cholesterol & -0.072 & 0.084 & 0.386 & - & - & - & - & - & - \\
\hline Constipation & - & - & - & - & - & - & 0.887 & 0.580 & 0.126 \\
\hline Nervous problems & 0.277 & 0.106 & 0.009 & -0.733 & 0.487 & 0.132 & -0.488 & 0.377 & 0.196 \\
\hline Skin problems & 0.025 & 0.091 & 0.782 & - & - & - & - & - & - \\
\hline Embolia & - & - & - & -0.238 & 0.198 & 0.229 & - & - & - \\
\hline Cardiac problems & - & - & - & - & - & - & -0.210 & 0.491 & 0.668 \\
\hline Asthma & - & - & - & - & - & - & -0.239 & 0.311 & 0.443 \\
\hline Non common & -0.170 & 0.198 & 0.389 & -2.984 & 1.156 & 0.010 & -0.774 & 1.526 & 0.612 \\
\hline Constant & -3.592 & 2.407 & 0.136 & -6.187 & 2.893 & 0.033 & 14.749 & 5.256 & 0.005 \\
\hline Total & 1.714 & 0.458 & 0.000 & 1.966 & 1.217 & 0.106 & 0.248 & 1.305 & 0.849 \\
\hline \multicolumn{10}{|l|}{ Interaction } \\
\hline Studies level & 0.071 & 0.104 & 0.496 & -0.088 & 0.315 & 0.781 & -0.244 & 0.450 & 0.589 \\
\hline Labour status & -0.158 & 0.191 & 0.407 & 0.147 & 0.217 & 0.500 & 0.213 & 0.139 & 0.126 \\
\hline
\end{tabular}


Table 4 Detailed results of the Blinder-Oaxaca decomposition (Continued)

\begin{tabular}{lccccccccc}
\hline Marital status & - & - & - & - & - & - & 0.571 & 0.339 & 0.093 \\
\hline Hypertension & -0.011 & 0.021 & 0.622 & - & - & - & - & - \\
\hline Varicose veins & -0.043 & 0.031 & 0.171 & - & - & - & - & - \\
\hline Osteoarthritis & 0.383 & 0.188 & 0.042 & 0.020 & 0.056 & 0.724 & 0.124 & 0.237 \\
\hline Bronchitis & -0.023 & 0.025 & 0.363 & 0.016 & 0.047 & 0.731 & - & - & - \\
\hline Diabetes & -0.004 & 0.012 & 0.718 & -0.012 & 0.130 & 0.926 & 0.181 & 0.201 \\
\hline Duodenal ulcer & -0.016 & 0.020 & 0.422 & 0.069 & 0.087 & 0.426 & - & - & - \\
\hline Cholesterol & -0.035 & 0.042 & 0.400 & - & - & - & - & - \\
\hline Constipation & - & - & - & - & - & - & 0.139 & 0.134 \\
\hline Nervous problems & 0.167 & 0.073 & 0.022 & -0.511 & 0.348 & 0.142 & -0.734 & 0.567 & 0.301 \\
\hline Skin problems & 0.001 & 0.005 & 0.846 & - & - & - & - & - \\
\hline Embolia & - & - & - & -0.118 & 0.125 & 0.344 & - & - \\
\hline Cardiac problems & - & - & - & - & - & - & -0.050 & 0.120 \\
\hline Asthma & - & - & - & - & - & - & -0.035 & 0.067 & 0.675 \\
\hline Non common & -0.146 & 0.170 & 0.389 & -2.549 & 0.993 & 0.010 & -0.432 & 0.852 \\
\hline Total & 0.186 & 0.343 & 0.588 & -3.026 & 1.067 & 0.005 & -0.268 & 1.116 \\
\hline
\end{tabular}

Catalonia, 1994-2006.

status [20,32]. The effect is minimized here, since the model used controls for education level and labour status. Finally, it has been argued that health interviews have an inherent selection bias, because of the death of some individuals before the interview. The probability of declaring a good or bad health status is conditioned to being alive, so there could be a selective truncation of the distribution function [33].

Also related with the use of health interviews is the comparability of the surveys. We used 1994 survey because it is the oldest one carried out in Catalonia that includes the EQ-5D instrument, and 2006 as it is the most recent. However, the 2006 questionnaire includes many more chronic conditions that the one in 1994. For that reason, we decided to include common conditions in the model, and to create a variable "non common conditions and others", to collapse the rest of the information. Regarding age groups, the ones used are common for the analysis of mortality data, separating younger and older adults, as well as younger and very old; those groups have distinctive epidemiological characteristics, and also different mean VAS, as shown.

\section{Conclusions}

The main implications of the results of our research concern the use of EQ-5D to measure population health over time, and with healthcare policy. As we have previously mentioned, health capital changes over time have been estimated using the same methodology in Catalonia and Sweden, multiplying the amount of life years gained (as a result of increased life expectancy) times the change in quality of life measured by EQ-5D over two cross-sections $[9,10]$. Respondents to the EQ$5 \mathrm{D}$ have reported worse health states over time, coherently with increases in the prevalence of chronic conditions and limitations. The main caveat of this way of proceeding is that utility values used in both studies have been the same in both cross-sections (utility values obtained in 1998 in Spain [34], and for the Swedish work, in 1997 in the UK [35]). So, the worsening in health capital obtained in those studies is a direct consequence of the increase in the prevalence of diseases. The results of our analysis highlight the increase in the prevalence effect, and the decrease in the severity effect, especially among older women, contradicting the results on the decrease of health capital. Using time varying tariffs may take into account the effect of changes in population preferences (i. e decrease in severity effect) across health problems.

Regarding health policy, our results on the increase in the prevalence effect, especially among older women, could be used when planning healthcare services, in particular, to address the health consequences of comorbidity. Perceived illness is a social phenomenon, and selfperceived morbidity provides valuable information on the relevance of disease to the individual. Although the stated worries, observed morbidity and the community's ranking of health problems information is of maximum importance for any health planner concerned with community health and dealing with health priority setting. 




Figure $\mathbf{2}$ Contribution to the gap in VAS by each variable to the prevalence, severity and interaction effects. Catalonia, 1994-2006.
Table 5 Gap in VAS, and contribution to the gap by prevalence, severity and interaction effects

\begin{tabular}{lll}
\hline & Linear model & Ordered probit model \\
\hline Men 15-44 & & \\
\hline Gap in VAS & 0.196 & 0.186 \\
\hline Prevalence effect & -0.082 & -0.102 \\
\hline Severity effect & 0.239 & 0.030 \\
\hline Interaction & 0.038 & -0.012 \\
\hline Women 65-74 & & \\
\hline Difference & -0.902 & -0.664 \\
\hline Prevalence effect & -0.575 & -0.699 \\
\hline Severity effect & 0.305 & 0.372 \\
\hline Interaction & -0.632 & -0.646 \\
\hline Women 75 \& more & & -1.182 \\
\hline Difference & -1.205 & -1.189 \\
\hline Prevalence effect & -1.117 & -0.088 \\
\hline Severity effect & -0.839 & -0.905 \\
\hline Interaction & -0.049 &
\end{tabular}

Catalonia, 1994-2006.

\section{Acknowledgements}

The authors are grateful the Agència de Salut Pública de Barcelona (ASPB) for providing the data, to Maarten Lindeboom (Department of General and Development Economics, Free University, Amsterdam) for his valuable suggestions on the statistical analysis, and all the members of the Centre for Health Economics (CHE), and the Health, Econometrics and Data Group (HEDG) of the University of York, for their comments on a previous version of this paper.

Sources of financial or other support: none.

\section{Author details}

${ }^{1}$ Agència de Salut Pública de Barcelona, Spain. ${ }^{2}$ Fundación Instituto de Investigación en Servicios de Salud, Spain. ${ }^{3}$ CIBER Epidemiología y Salud Pública (CIBERESP), Spain. ${ }^{4}$ Departamento de Métodos Cuantitativos en Economía y Gestión, Universidad de Las Palmas de Gran Canaria, Spain. ${ }^{5}$ Departament d'Economia i Empresa, Universitat Pompeu Fabra, Spain.

${ }^{6}$ Centre de Recerca en Economia i Salut, Universitat Pompeu Fabra, Spain.

\section{Authors' contributions}

AGA performed the statistical analysis, and drafted the manuscript. JP lead the statistical analysis. VO lead the framing of the study, and the discussion of the results. All authors participated in the conception of the study, and read and approved the final manuscript.

\section{Competing interests}

The authors declare that they have no competing interests.

Received: 20 July 2010 Accepted: 23 May 2011 Published: 23 May 2011

\section{References}

1. Cutler DM, Richardson E: The value of health: 1970-1990. Am Econ Rev 1998, 97-100, AEA Papers and Proceedings.

2. Sala-i-Martin X, Doppelhofer G, Miller R: Determinants of long-term growth: a Bayesian averaging of classical estimates (BACE) approach. Am Econ Rev 2004, 45:827-38

3. World Health Organization: Macroeconomics and health: Investing in health for economic development. Report of the Commission on Macroeconomics and Health Geneva: World Health Organization; 2001. 
4. Grossman M: On the concept of health capital and the demand for health. J Pol Economy 1972, 80(2):223-55.

5. IDESCAT: Estadística bàsica de Catalunya. Demografia i qualitat de vida. Esperança de vida.[http://www.idescat.cat/dequavi/?TC=444\&V0=2\&V1=1], Last accessed: 16/3/10.

6. Barsky AJ: The paradox of health. N Engl J Med 1988, 318(7):414-8.

7. Sen A: Health: perception versus observation. Br Med J 2002, 324(7342):860-1.

8. Case A, Paxson C: Sex differences in morbidity and mortality. Demography 2005, 42(2):189-214.

9. Zozaya N, Oliva J, Osuna R: Measuring changes in health capital. Documento de Trabajo 2005-15 Madrid: FEDEA; 2005.

10. Burström $K$, Johannesson $M$, Diderichsen $F$ : The value of the change in health in Sweden 1980/81-1996/97. Health Econ 2003, 12(8):637-54.

11. EQ-5D. A standardized instrument for use a a mesure for health outcome. [http://www.eurogol.org/home.html], Last accessed 8/4/11.

12. Blinder AS: Wage discrimination: reduced form and structural estimates. $J$ Human Res 1973, 8:436-55.

13. Oaxaca R: Male-female wage differentials in urban labour markets. Int Econ Rev 1973, 14:693-709.

14. Jann BA: The Blinder - Oaxaca decomposition for linear regression models. The Stata Journal 2008, 8(4):453-79.

15. Fairlie RW: An extension of the Blinder - Oaxaca decomposition technique to logit and probit models. Center Discussion Paper no. 873 New Haven, CT: Yale University; 2003.

16. Bauer TK, Sinning M: An extension of the Blinder-Oaxaca decomposition to nonlinear models. Advances in Statistical Analysis 2008, 92:197-206.

17. Manning WG, Mullahy J: Estimating log models: to transform or not to transform? J Health Econ 2001, 20:461-494.

18. Shaw JW, Johnson JA, Coon SJ: US valuation of the EQ-5D health states: development and testing of the D1 valuation model. Medical Care 2005 43(3):203-220

19. Murray $C J L$, Chen $L C$ : Understanding morbidity change. Pop Develop Rev 1992, 18(3):481-503.

20. Kahneman D, Krueger AB: Developments in the measurement of subjective well-being. J Econ Persp 2006, 20(1):3-24.

21. Baker M, Stabile M, Deri C: What do self-reported, objective measures of health measure? Working paper 8419 Cambridge, MA: National Bureau of Economic Research; 2001.

22. Fairlie RW: The absence of the african-american owned business: an analysis of the dynamics of self-employment. J Labor Econom 1999, 17(1):80-108.

23. Jurges $\mathrm{H}$ : True health vs response styles: exploring cross-country differences in self-reported health. DIW Berlin. Discussion papers 68 Berlin: German Institute for Economic Research; 2006

24. Madden D: Gender differences in mental well-being: a decomposition analysis. HEDG working paper 08/08 York: University of York; 2008.

25. O'Donnell O, van Doorslaer E, Wagstaff A, Lindelow M: Analyzing health equity using household survey data. A guide to techniques and their implementation Washington, DC: The World Bank; 2008.

26. O'Donnell O, van Doorslaer $E$, Wagstaff A: Decomposition of inequalities in health and healh care. Jones A. Elgar Companion to Health Economics Chichester: Edward Elgar; 2006.

27. Idler EL, Benyamini Y: Self-rated health and mortality: a review of twentyseven community studies. J Health Soc Behav 1997, 38(1):21-37.

28. DeSalvo KB, Jones TM, Peabody J, McDonald J, Finn S, Fan V, He J, Muntner $P$ : Health care expenditure prediction with a single item, selfrated health measure. Med Care 2009, 47(4):440-7.

29. Hernández Quevedo C, Jones AM, Rice N: Reporting bias and heterogeneity in self-assessed health. Evidence from the British Household Panel Survey. Health, Econometrics and Data Group (HEDG) Working paper $05 / 04$ York: University of York; 2005.

30. Bago d'Uva T, O'Donnell O, van Doorslaer E: Differential health reporting by education level and its impact on the measurement of health inequalities among older Europeans. Health, Econometrics and Data Group (HEDG) Working paper 07/28 York: University of York; 2008.

31. Lindeboom M, van Doorslaer E: Cut-point shift and index shift in selfreported health. IZA Discussion Paper No. 1286; Tinbergen Institute Working Paper No. 2003-042/3 Amsterdam: Tinbergen Institute; 2004
32. Mackenbach JP, Looman CWN, van der Meer JBW: Differences in the misreporting of chronic conditions, by level of education: the effect on inequalities in prevalence rates. Am J Public Health 1996, 86:706-11.

33. Heckman J: Sample selection bias as a specification error. Econometrica 1979, 47:153-61.

34. Badia X, Roset M, Montserrat S, Herdman M, Segura A: [The Spanish version of EuroQol: a description and its applications. European Quality of Life scale]. Med Clin (Barc) 1999, 112(Suppl 1):79-85.

35. Dolan P: Modeling valuations for EuroQol health states. Med Care 1997 35:1095-108

\section{Pre-publication history}

The pre-publication history for this paper can be accessed here:

http://www.biomedcentral.com/1472-6963/11/116/prepub

\section{doi:10.1186/1472-6963-11-116}

Cite this article as: García-Altés et al:: The evolution of health status and chronic conditions in Catalonia, 1994-2006: the paradox of health revisited using the Blinder - Oaxaca decomposition. BMC Health Services Research 2011 11:116.

\section{Submit your next manuscript to BioMed Central and take full advantage of:}

- Convenient online submission

- Thorough peer review

- No space constraints or color figure charges

- Immediate publication on acceptance

- Inclusion in PubMed, CAS, Scopus and Google Scholar

- Research which is freely available for redistribution

Submit your manuscript at www.biomedcentral.com/submit
Ciomed Central 